\title{
Online and Other ICT-based Training Tools for Problem-solving Skills
}

\author{
http://dx.doi.org/10.3991/ijet.v11i06.5340 \\ Maria Karyotaki, Athanasios Drigas \\ N.C.S.R. 'Demokritos', Institute of Informatics and Telecommunications, Telecoms Lab - Net Media Lab
}

\begin{abstract}
Problem-solving requires creative skills, critical thinking as well the ability to implement ideas and theories in practical ways. Moreover, interactive and self-managed problem-solving experiences promote students' motivation as expressed through the developmental progression of learners' metacognitive skills, such as self-monitoring and self-reinforcement. Effective learning based on constructivist didactics, encompassing self-organized learning in combination with active and creative problem-solving in collaborative settings, advances students' concomitant cognitive and meta-cognitive processes. Hence, students' coconstruction of knowledge embodied in social dynamic learning environments, such as school-based tasks leverage the semantic relationships rising from exercising, verifying and testing of knowledge through information sharing and discussion. Future studies should focus on designing interactive, adaptable, ill-defined, real-world learning environments to elicit students' cognitive and meta-cognitive processes as a key factor for the effective training of problemsolving skills.
\end{abstract}

Index Terms-problem-solving skills, cognitive training, collaborative problem-solving.

\section{TANGIBLE PROBlem SOLVING SySTEMS}

Esteves et al. initiate the Artifact Tool and Body (ATB) Framework for quantifying and classifying users' strategies, reasoning abilities and overall performance in tangible problem-solving tasks. Such tasks involve users' employing a set of complementary actions, such as exploring, testing, annotating or re-structuring a system state based on its physical representation. Current video-coding framework categorizes hand actions and classifies behaviors, in other words epistemic actions, while users complete a physical jigsaw puzzle. Moreover, the ATB framework was empirically verified for its reliability, validity and predictive power as well as it was qualified for guiding the design of tangible systems in the future. The aforementioned tangible systems could encompass diverse and hybrid problem-solving tasks, including nonspatial or digital information elements.

\section{GAMES}

Adachi et al. made an empirical research on the longitudinal association between sustained strategic video game play and the promotion of adolescents' self-reported problem solving skills as well as higher academic grades. The results of this study support that playing strategic video games predicts higher self-reported problem solving skills, thus, higher academic grades, although adolescents with higher problem solving skills tend to diminish the time spent in strategic video games play over time. Stu- dents' training of their problem solving skills is concurrent with the development of their executive function of inhibitory control. Therefore, educators should incorporate such cognitive training tools in order to address to students' individualized problem solving skills development.

$\mathrm{Fu}$ Lin et al. designed a multi-material-based learning system (MBLS), consisting of animated game-based material and static text material, in order to explore how the learning materials of a problem-solving activity, influence learning performance. The MBLS was found effective in training learner's problem solving skills through integrating cross-domain knowledge and real-time information sharing from the web. Furthermore, such interactive and adaptable learning environments increase user's motivation.

Deniz Eseryel et al. designed McLarin's Adventures MMOG, a massively multiplayer online game, addressing complex problem-solving skill development in interdisciplinary STEM (Science, Technology, Engineering and Mathematics) secondary education. Cognitive regulation scaffolds are a determining factor in reducing students' cognitive load as they were trying to comprehend the dynamic interrelationships among the large number of variables affecting the problem-state. System dynamic modeling in combination with stealth, embedded assessment with textual and graphical feedback propose an effective digital game design in order to enhance students' complex problem-solving skill acquisition.

Hwang et al. incorporated a web-based informationsearching question and a mini-game into an online problem-solving gaming activity with the aim to support elementary students' learning achievements and motivation. This multiplayer competition, online game consisted in a board game interface, combining a learning management mechanism, a gaming mechanism and a link to a search engine in order to provide multiple modes of scaffolding to its users. The system had a positive influence on both students' learning achievements and learning attitude towards their subject material as well as on their overall motivation and engagement in the problem solving activity. Furthermore, it is highly recommended that students use collaborative games, such as the Classroom Multiplayer Presential Game (CMPG) or online competitive games for promoting learners' interactions in different locations or classes.

Yang performed an empirical study on the effectiveness of a digital game, the "SimCity Societies", in improving students' problem solving skills as well their learning motivation and academic achievement. Results verified the development of students' problem solving skills, notably, in a rather extended period of time, a full semester. 
Also, their learning motivation was enhanced as far as the task value and students' self-efficacy is concerned. Nevertheless, their academic achievement neither deteriorated nor improved. Overall, digital game-based learning (DGBL) should be applied in a more holistic school setting, wherein the learning objectives, strategies and evaluation methods co-construct students' higher order thinking skills.

Hou studied learners' reflective behavior patterns in role-playing simulation games with realistic problemsolving scenarios as well as the learning processes taking place in each one of the three rising clusters of learners. Given that learners' problem-solving strategies are related to players' flow experience in the observation, exploration, analysis and experimental manipulation of the simulation software operations, the study aimed at examining the aforementioned learning processes in detail. It turned out that as learners explore and analyze the situated scenarios as well as complete the virtual manipulation tasks, the cognitive processes involved, such as memory retrieval and alignment may diminish students' degree of game immersion. As with impatient students who need more cognitive scaffoldings in order to enhance their learning effectiveness, students with lower flow may not focus on the reflective strategies of analyzing and testing. Thus, appropriate simulation games that elevate students' level of flow have a positive effect on players' learning motivation, immersion and reflective behavior patterns. The scaffolding provided by the simulation games in science education should consider learners' prior knowledge as well as encompass a variety of timely guidance and context features to evoke students' fluency and concentration.

Martinovic et al. describe a method for categorizing single-player computer games according to the main cognitive functions engaged in during gaming by the players. This research established the cognitive classification categories of 221 computer and video games included in the Online Training and Education Portal (OTEP). The fact that each game was linked to a primary and a secondary cognitive skill proclaims that the games can be considered a useful cognitive tool, both for training and evaluation purposes. Furthermore, games can be used both for training gamers' cognitive skills and for maintaining users' interest and motivation. Consequently, the game industry in concordance with researchers can provide the necessary tools for structuring players' cognitive profiles through the gaming performance of the latter. In other words, children can take the benefit of personalized and dynamic gaming experiences based on their interests, needs and everchanging cognitive capabilities.

\section{STAND ON APPLICATIONS}

Boujarwah et al. present an individualized intervention for the improvement of autistic students' social skills, based on a crowdsourced social script model. The authors implemented the Amazon's Mechanical Turk in order to design, develop and evaluate an interactive software module with a social script encompassing a complex, problem solving process. The Reflex instructional module was evaluated on account of the variety of steps, obstacles and solutions provided in the script, with obstacle and solution data harnessing the highest richness scores.

\section{WEB}

Nordin et al. refer to the importance of adopting online Problem Based Learning for the enhancement of Malaysian engineering students' problem solving skills, although such claim necessitates further scientific illustration. More specifically, online Problem Based Learning needs to be clarified as far as its learning content and teaching methodology, is concerned.

Argelagos et al. implemented a long-term instructional program, consisting of a scaffolding instructional method in a web-based learning environment, designed and embedded with the aim to develop secondary students' Information Problem Solving (IPS) skills. The experimental group was found to be more frequently occupied with the part of the activity, called "defining the problem" in an attempt to specify the information needed. Moreover, the aforementioned group invested much more time than the control group in "scanning and processing the information" as well as in "organizing and presenting information". In other words, the intervention raised students' efficiency in searching and transforming information as well as it improved their task performance.

Kim et al. made a thorough analysis on several facets of scaffolding related to problem solving in technologyenhanced classrooms. According to this research, scaffolding is a dynamic, complementary process, depending on the teacher, the peers and the technological means, as a whole. Evidently, scientists need to counter everyday classroom adversities with a comprehensive framework that could link, effectively, problem solving, inquiry and technology.

Raes et al. present an intervention aiming at the enhancement of secondary students' information problem solving during web based inquiry learning. Current research compared two modes of scaffolds, technologyenhanced and teacher-enhanced scaffolding in relation to students' gender and level of prior knowledge. The results of the study showed teacher-enhanced scaffolding to be a determining factor in domain-specific knowledge acquisition, whereas technology-enhanced scaffolding improved students' metacognitive awareness. Moreover, multiple scaffolding seems to be beneficial for dealing with gender differences as well as students' level of prior knowledge in reference to learning outcomes. Advantaged students were efficient enough in handling content knowledge, regardless of the scaffolding condition, whereas boys performed better under the teacher-scaffolded condition.

Wopereis et al. implemented process worksheets accompanied with driving questions as part of a web based, professional task instruction aiming at the improvement of students' information problem solving (IPS) performance. Results of the study showed that the aforementioned embedded instruction had a positive effect on students' information-scanning as well as on students' reflecting during the information problem solving process. More specifically, frequent and efficient regulation of the problem solving process was related to students' quality of learning.

Jewpanich et al. developed and evaluated a projectbased learning model for enhancing undergraduate students' problem solving skills by using discussion and lesson-learned methods through the social media (PBLDLL SoMe Model). The Model was found to be cohesive in relation to its design, process and overall output. More- 
over, it was qualified as being consistent and effective in promoting students' overall achievement and problem solving skills.

Kuo et al. integrated two learning models, cognitive apprenticeship, a set of constructive questions with modeling, coaching, scaffolding, articulation, reflection and exploration processes in combination with collaborative learning. The purpose of the intervention laid on the use of a hybrid learning strategy so as to improve students' information-searching ability, and thus their web-based problem-solving competence. Such hybrid approach required the implementation of the web-based informationsearching behavior analyzing system, Meta-Analyzer, as a sound instruction strategy in a collaborative learning environment. The experimental group showed enhanced problem solving skills, expressed less stress in articulating their problem solving process in front of the whole class and grew in confidence as to encountering any real-life problems. Furthermore, middle- and low-achievement students were benefited, the most, from the collaborative mechanism in terms of their keyword-adopting ability and eventually, their ability to construct knowledge. Results also showed that students' social science course attitude was improved and, in effect, it was related to students' advanced learning performance. Effective cooperative learning resides in group member interdependence, the latter being a facilitator for all students to think aloud when conducting the cognitive apprenticeship process.

$\mathrm{Gu}$ et al. present an intervention framework with the aim to develop primary students' problem solving skills in a collaborative learning environment. This framework involved strategies and ICT tools, such as building students' social skills in combination with computer-based scaffolds. The latter cognitive tool, through its planning template (Mindmap) and its question prompts, provided support to enhance students' elaboration, reflection and making of evidence-based arguments, during the whole problem solving process. The experimental group was superior to the control group in terms of their ability to make a detailed plan, to provide illustrative evidence as well as to provide the source of their evidence. In relation to the transfer effect of students' problem solving skills, the experimental group outperformed the control group in their ability to interpret, present and provide reasonable solutions while dealing with a new group activity. Far and foremost, teachers have a critical role in creating an appropriate domain knowledge background as well as a constructivist school setting in order to scaffold students' cognitive and meta-cognitive skills.

Stary et al. proclaim that problem solving is the highest competence, learners can acquire in a collaborative and interactive learning environment. More specifically, current intervention supports the notion of intertwining selforganized learning and peer/facilitator communication while developing and implementing e-learning contract. The Scholion platform and the eCOOL platform facilitate communication and content management of e-learning contracts. E-learning contracts embedded within the elearning platform should entail a clear structure as far as the learning process and its expected achievements, are concerned. Moreover, e-learning contracts need to provide information about the planned activities and social interactions involved in the accomplishment of the learning goals. Furthermore, the authors recommend that learners interfere with the construction of learning contracts, lever- aging the social dynamics of a semantic e-learning environment for enhancing creative problem solving capabilities.

Chen et al. explain the cognitive processes occurring when facing with ill-structured problem-solving in elearning. Individual's perception, memory recall and reasoning as well as working memory (WM) and long-term memory (LTM) are interdependent key factors in solving ill-structured problems, all of which are influenced by metacognitive self-assessment and self-regulation. Computer-based cognitive tools such as question prompts, concept maps and mind mapping tools facilitate illstructured problem solving processes. Moreover, the adoption of adequate teaching techniques and resources, such as pre-training sessions for novice learners, interactive nonlinear explorative activities, scaffolding strategies and dynamic organizers can be integrated in solving illstructured problems. As a result, learners' cognitive characteristics should be taken into account in complex problem solving so as to provide the formers with prosperous e-learning experiences for constructing new knowledge.

Furthermore, Lee et al. made a research on the cognitive regulatory sub-processes employed by groups in a synchronous Computer-Supported Collaborative Learning (CSCL) context. Within high quality social regulation contexts, problem solving turns, implicitly, into a synergistic factor for knowledge co-construction with respect to the groups' high level cognitive regulation. Shared planning, monitoring and evaluation processes taking place either in a socially shared regulation or in other-regulation CSCL setting, were investigated. Results of the study showed the importance of shared plans and goals as well as groups' frequent and high quality content monitoring in elevating overall cognitive regulation quality. High quality content understanding may have been fostered by immediate feedback and gradual elaboration of the task response, through group discourse. Moreover, goal acceptance through dynamic social interaction played an important role in acquiring successful goal achievement among group members.

Likewise, Malmberg et al. explored the importance of the socially shared regulation of learning (SSRL) as part of an effective computer-supported collaborative learning (CSCL) context. Researchers looked into the cognitive, motivational and emotional strategies implemented by groups in order to be able to regulate in joint agreement, the challenges that rose in the course of their social interaction. Thus, through investigating how groups regulate the challenges that they identify, specific aspects in the SSRL are enlightened and collaboration becomes more successful. The results of the study focus on the importance of regulating the cognitive and motivational aspects of the collaboration. More specifically, both high and low performing groups used a variety of SSRL strategies so as to regulate their motivational challenges as a prerequisite for enhancing, consequently, their cognitive processes. As a result, the type of challenge, such as the design of appropriate scripts or prompts in online learning situations may stimulate group interaction and their endeavor in the fulfillment of their common learning goals. However, successful collaboration stems from the group recognizing the social challenges in each learning situation and adapting to the varying targets of SSRL across the collaborative tasks. 
Xibin Han et al. examined the role of the instructor as a contributing factor for stimulating learners' higher level cognitive activities, such as problem solving skills in a web-based learning platform. The researchers employed the learning analytics approach in order to investigate both the instructor's and students' behavioral attributes recorded in a learning management system (LMS). A Structural Equation Modeling (SEM) was established to analyze group interactive activities among instructors and students as well as the relationship between those activities. Evidently, this study constructed five factors about instructor's activities and students' engagement activities in the online learning environment. According to the results of the study, instructor's course preparation has a strong influence on students' viewing activities, whereas instructor's guidance and assistance activities have significant impact on students' completing learning tasks. More specifically, the nature of the learning task assigned to students is a key factor that determines the level of student engagement as well as receiving feedback from the instructor is also vital for students' involvement in learning reflection. Thus, instructors should consider students' characteristics and real learning needs in order to design effective learning contents that may increase interaction among instructors and students. Moreover, monitoring students' learning processes and implementing constructive and timely guidance led to students' simultaneous improvement in their level of engagement and level of learning.

$\mathrm{Gu}$ et al. examined the importance of the group processes modeled in a computer-supported collaborative learning (CSCL) environment with the use of roles. The group cognitive processes on the basis of six discrete roles assignment depict the joint meaning-making process occurring in a collaborative problem solving activity. Two online systems were implemented in order to record the group discussions. The results showed that students were responsible for most core tasks and core functions corresponding to their assigned roles. Moreover, the scripted roles were helpful in engaging students in collaborative problem solving. Future studies should thoroughly examine the factors that influence students' capability of acting the assigned roles (COA) as well as their participation degree (PD) for each role.

\section{RESEARCH HighLIGHTS}

Problem solving skills training is related to students' improved academic achievement, learning motivation and cognitive performance, in general. Most researchers in the field of ICTs, address this multi-purpose issue of problem solving as a complex construct, made up of several cognitive processes. Such processes may encompass searching, transforming, presenting and reflecting on information as part of an individual self-regulated learning context as well as planning, monitoring and evaluating the content of the task in a Computer-Supported Cooperative Learning environment (CSCL). Overall, studies show that educators' and instructors' adaptable learning tasks, accompanied by frequent and efficient regulation of cognitive processes, create a stimulating and rather personalized learning experience. The more stimulating and compatible with learner's cognitive abilities the learning experience, the more effective it is for students' learning achievements. In addition to appropriate scripts, question prompts, planning templates and multiple scaffolding destined to each learner, respectively, cooperative problem solving activities necessitate students' group discourse for sharing plans and goals. Common learning goals fulfillment is relative to the group members' positive interdependence and individual accountability. By creating, thus, adequate collaborative problem-solving experiences, educators, promote the construct of collaborative problem-solving skills.

\section{CONCLUSIONS}

Problem-solving requires skills ranging from creativity, over-analytical skills to skills that allow learners to put theories and ideas into practice. As learning how to solve problems in life occurs in communities or organizations, social interactions need to be facilitated and scaffolded during problem-solving learning tasks. Thus, collaborative problem solving tasks should be embedded in interactive learning environments that support information sharing and discussion among group members and their facilitators. As a result, learners have more opportunities to promote their cognitive and meta-cognitive skills, such as critical thinking, problem-solving, decision making, selfawareness and self-reflection.

\section{REFERENCES}

[1] Adachi, P.J.C. and Willoughby, T. : "More than just fun and games: The longitudinal relationships between strategic video games, self-reported problem solving skills and academic grades", J Youth Adolescence, vol. 42, pp. 1041-1052, (2013). http://dx.doi.org/10.1007/s10964-013-9913-9

[2] Fu Lin, C. Hsin Hung, Y. and Chang, R. I. : "Effect Analysis of a Multi-Material Approach to a Problem-Solving Learning System", International Journal of Computer Trends and Technology (IJCTT), vol. 4, issue 5, pp. 1450-1456, (2013).

[3] Deniz Eseryel, X. G. Ifenthaler, D. and Law, V. : "Dynamic Modeling as a Cognitive Regulation Scaffold for Developing Complex Problem-Solving Skills in an educational Massively Multiplayer Online Game Environment", J. Educational Computing Research, Vol. 45, number 3, pp. 265-286, (2011). http://dx.doi.org/10.2190/EC.45.3.a

[4] Hwang, G.-J., Wu, P.-H. and Chen, C.-C. : “An online game approach for improving students' learning performance in webbased problem-solving activities", Computers \& Education, vol. 59, pp. 1246-1256, (2012). http://dx.doi.org/10.1016/j.compedu. 2012.05.009

[5] Yang, Y.-T. C. : "Building virtual cities, inspiring intelligent citizens: Digital games for developing students' problem solving and learning motivation", Computers \& Education, vol. 59, pp. 365-377, (2012). http://dx.doi.org/10.1016/j.compedu.2012.01.012

[6] Hou, H.-T. : "Integrating cluster and sequential analysis to explore learners' flow and behavioral patterns in a simulation game with situated-learning context for science courses: A video-based process exploration", Computers in Human Behavior, vol. 48, pp. 424-435, (2015). http://dx.doi.org/10.1016/j.chb.2015.02.010

[7] Martinovic, D. Ezeife, C. I. Whent, R. Reed, J. Burgess, G. H. Pomerleau, C. M. Yang, Y. and Chaturvedi, R. : "“Criticproofing" of the cognitive aspects of simple games", Computers \& Education, vol. 72, pp. 132-144, (2014). http://dx.doi.org/10.1016/ j.compedu.2013.10.017

[8] Boujarwah, F. A. Abowd, G. D. and Arriaga, R. I. : "Socially Computed Scripts to Support Social Problem Solving Skills", Session: Social Support \& Collaboration, CHI 2012, May 5-10, 2012, Austin, Texas, USA.

[9] Nordin, N. M. and Subramaniam, S. T. S. : "Problem Based Learning Approach in the Designing of E-content for Engineering Courses", Asian Social Science, vol. 9, number 10, pp. 300-306, (2013). http://dx.doi.org/10.5539/ass.v9n10p300

[10] Argelagos, E. and Pifarre, M. : "Improving Information Problem Solving skills in Secondary Education through embedded instruc- 
tion”, Computers in Human Behavior, vol. 28, 515-526, (2012). http://dx.doi.org/10.1016/j.chb.2011.10.024

[11] Kim, M. C. and Hannafin, M. J. : "Scaffolding problem solving in technology-enhanced learning environments (TELEs): Bridging research and theory with practice", Computers and Education, vol. 56, pp. 403-417, (2011). http://dx.doi.org/10.1016/j.compedu. 2010.08.024

[12] Raes, A. Schellens, T. De Wever, B. and Vanderhoven, E. : "Scaffolding information problem solving in web-based collaborative inquiry learning", Computers \& Education, vol. 59, pp. 82-94, (2012). http://dx.doi.org/10.1016/j.compedu.2011.11.010

[13] Wopereis, I. Brand-Gruwel, S. and Vermetten, Y. : "The effect of embedded instruction on solving information problems", Computers in Human Behavior, vol. 24, pp. 738-752, (2008). http://dx.doi.org/10.1016/j.chb.2007.01.024

[14] Jewpanich, C. and Piriyasurawong, P. : “Project-Based Learning Using Discussion and Lesson-Learned Methods via Social Media Model for Enhancing Problem Solving Skills", International Education Studies, vol. 8, n. 6, pp. 24-31, (2015). http://dx.doi.org/10.5539/ies.v8n6p24

[15] Kuo, F.-R. Hwang, G.-J. and Lee, C.-C. : "A hybrid approach to promoting students' web-based problem-solving competence and learning attitude", Computers \& Education, vol. 58, pp. 351-364, (2012). http://dx.doi.org/10.1016/j.compedu.2011.09.020

[16] Gu, X. Chen, S. Zhu, W. and Lin, L. : “An intervention framework designed to develop the collaborative problem-solving skills of primary school students", Education Tech Research Dev., vol. 63, pp. 143-159, (2015). http://dx.doi.org/10.1007/s11423-014-9365$\underline{2}$

[17] Stary, C. and Weichhart, G. : "An e-learning approach to informed problem solving”, Knowledge Management \& E-Learning: An International Journal, vol. 4, number 2, pp. 195-215, (2012).

[18] Chen, J. and Li, X. : "Research on Solving Ill-Structured Problems for e-Learning: Cognitive Perspectives", International Journal of Information and Education Technology, Vol. 5, Number 12, pp. 920-923, (2015). http://dx.doi.org/10.7763/IJIET.2015.V5.638

[19] Lee, A. O’Donnell, A. M. and Kempler Rogat, T. : "Exploration of the cognitive regulatory sub-processes employed by groups characterized by socially shared and other-regulation in a CSCL context", Computers in Human Behavior, vol. 52, pp. 617-627, (2015). http://dx.doi.org/10.1016/j.chb.2014.11.072

[20] Malmberg, J. Jarvela, S. Jarvenoja, H. and Panadero, E. : "Promoting socially shared regulation of learning in CSCL: Progress of socially shared regulation among high- and low-performing groups", Computers in Human Behavior, vol. 52, pp. 562-572, (2015). http://dx.doi.org/10.1016/j.chb.2015.03.082

[21] Xibin Han, J.-M. Yang, J. and Cheng, J. : "Examining the necessary condition for engagement in an online learning environment based on learning analytics approach: The role of the instructor", Internet and Higher Education, vol. 24, pp. 25-34, (2015).

[22] Gu, X. Shao, Y. Guo, X. and Lim, C. P. : "Designing a role structure to engage students in computer-supported collaborative learning”, Internet and Higher Education, vol. 24, pp. 13-20, (2015). http://dx.doi.org/10.1016/j.iheduc.2014.09.002

\section{AUTHORS}

Athanasios Drigas is a Research Director at IITN.C.S.R. Demokritos. He is the Coordinator of Telecoms $\mathrm{Lab}$ and founder of Net Media Lab since 1996. From 1990 to 1999 he was the Operational manager of the Greek Academic network. He has been the Coordinator of Several International Projects, in the fields of ICTs, and eservices (e-learning, e-psychology, e-government, einclusion, e-culture etc). He has published more than 270 articles, 7 books, 25 educational CD-ROMs and several patents. He has been a member of several International committees for the design and coordination of Network and ICT activities and of international conferences and journals. (e-mail: dr@iit.demokritos.gr).

M. Karyotaki is with N.C.S.R. 'Demokritos', Institute of Informatics and Telecommunications, Telecoms Lab Net Media Lab, Agia Paraskevi, 153 10, Athens, Greece (e-mail: karyotakimaria@gmail.com)

Submitted 07 December 2015. Published as resubmitted by the athor 13 February 2016. 